\title{
THIGH PAIN DESPITE BONE INGROWTH INTO UNCEMENTED FEMORAL STEMS
}

\author{
R. L. BARRACK, M. JASTY, C. BRAGDON, T. HAIRE, W. H. HARRIS
}

From Massachusetts General Hospital and Harvard Medical School, Boston

\begin{abstract}
Six porous-coated, uncemented femoral components were revised at a mean of 34.5 months for persistent thigh pain. At operation the stems were rigidly stable, difficult to extract, and showed good bony ingrowth. The four men and two women, with an average age of 59 years, all had thigh pain starting within the first year, progressive over time and unresponsive to conservative measures.

These cases show that rigid fixation with good bony ingrowth does not guarantee the clinical success of a porous-coated uncemented femoral stem.
\end{abstract}

Porous-coated uncemented femoral stems rely on tissue ingrowth to achieve stability (Haddad, Cook and Thomas 1987). The presumption is that good bone ingrowth will provide rigid fixation and clinical success (Engh, Bobyn and Glassman 1987), but it is now recognised that a significant percentage of patients have persistent thigh pain and limping after uncemented hip replacement (Engh et al 1987; Callaghan, Dysart and Savory 1988; Campbell et al 1992). Residual pain has been reported in as many as $30 \%$ to $40 \%$ of patients two years postoperatively (Haddad et al 1990). The cause of the pain is not clear, although it has been suggested that failure to achieve bone ingrowth, or at least stable fibrous ingrowth, leads to failure (Engh, Massin and Suthers 1990).

We report six patients with persistent pain and limping severe enough to require revision who were found to have rigid fixation and histological proof of good bone ingrowth.

\section{PATIENTS AND METHODS}

The six cases were the patients of four surgeons; their clinical data are presented in Table I. All had primary femoral reconstructions, three for hip fracture and three for osteoarthritis, and they all had the onset of thigh pain

R. L. Barrack, MD, Associate Professor of Orthopaedic Surgery

Tulane University Medical School, New Orleans, Louisiana 70112 , USA.

M. Jasty, MD, Clinical Assistant Professor of Orthopaedic Surgery Harvard Medical School, Boston, Massachusetts 02114, USA.

C. Bragdon, BS, Senior Research Technologist

T. Haire, BS, Research Technologist

W. H. Harris, MD, Chief, Hip and Implant Surgery Unit

Orthopaedic Biomechanics Laboratory, Massachusetts General

Hospital, Boston, Massachusetts 02114, USA.

Correspondence should be sent to $\mathrm{Dr} \mathrm{W}$. H. Harris.

(C) 1992 British Editorial Society of Bone and Joint Surgery

$0301-620 X / 92 / 4418 \$ 2.00$

J Bone Joint Surg [Br] 1992; 74-B : 507-10 and limping within one year of operation. Pain and limping were the primary indication for revision in four cases, but case 5 had also developed lysis around the femoral component, while in case 6 the acetabular liner had displaced from its metal backing.

After extraction, the femoral components were placed in formalin, then dehydrated in graded alcohol solutions and embedded in methacrylate. Ten to 20 sections were cut from the porous-coated portion of each component and ground down to provide thin specimens. Tissue ingrowth was measured using either computerassisted quantification of histological sections (Cook et al 1988) or back-scattered scanning electron microscopy (Jasty et al 1989).

\section{RESULTS}

Revision had been at a mean of $\mathbf{3 4 . 5}$ months after the primary arthroplasty. Bone ingrowth was seen in $4 \%$ to $50 \%$ of the porous-coated areas (mean $28 \%$ ). The stems of the revision prostheses were all fixed with cement; the results are given in Table I. Four of the six patients had adequate relief of pain after revision.

Illustrative case report. A 61-year-old woman (case 1) sustained a displaced fracture of the left femoral neck which had been treated by a PCA bipolar prosthesis (Howmedica, Rutherford, New Jersey). Eleven months later, because of diffuse hip pain, this was revised to a PCA total hip. The stem of the original femoral component appeared to be well fixed at surgery and was left in place. A postoperative dislocation was treated by closed reduction.

The patient never became painfree and by two years required crutches. Aspiration of the hip gave negative cultures; bone scanning showed only slightly increased uptake at the tip of the implant. At four years the patient remained on crutches with severe activity-related thigh pain. Radiographs showed no subsidence but there was 


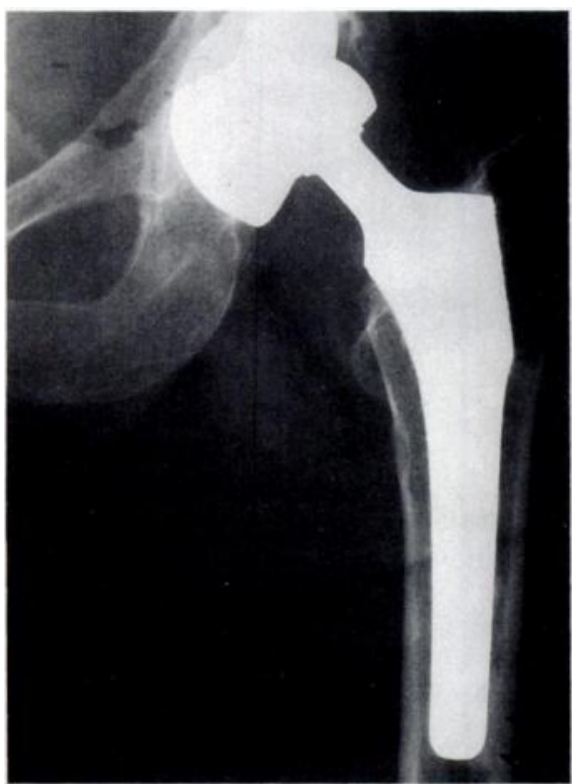

Fig. 1a

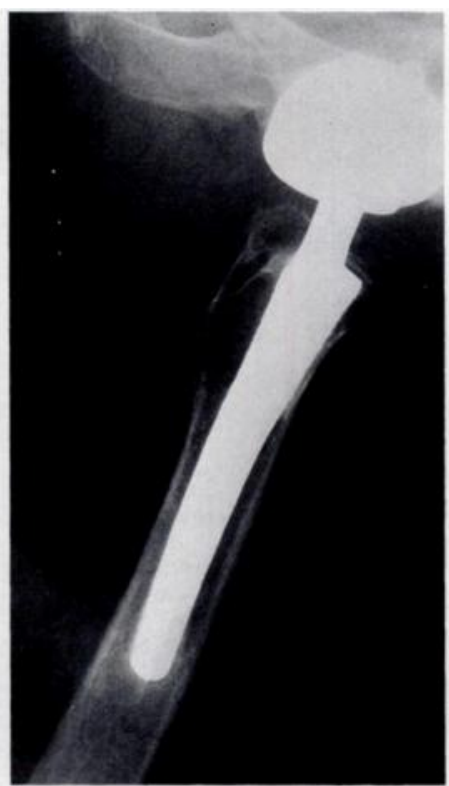

Fig. 1b

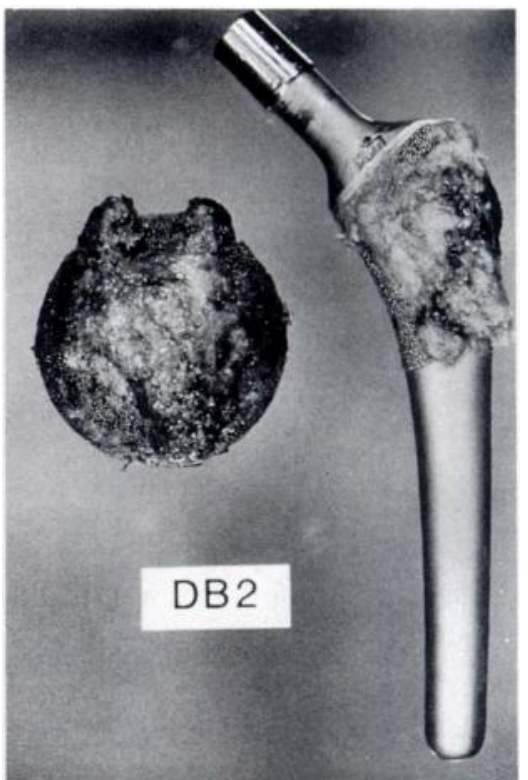

Fig. 1c

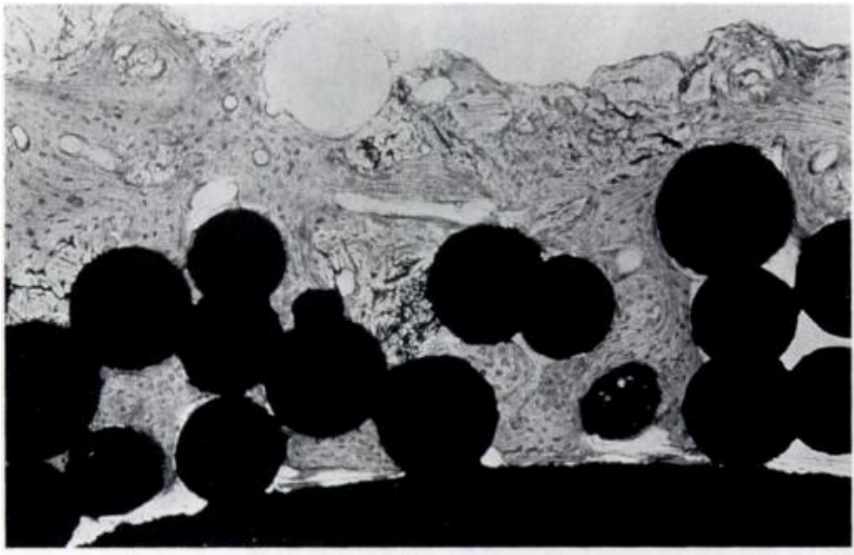

Fig. 1d
Figures $1 \mathrm{a}$ and $1 \mathrm{~b}$ - Radiographs of a PCA uncemented hip replacement which had given persistent pain and limping for over four years. The anteroposterior view shows some endosteal new bone formation lateral to the tip of the stem. The lateral radiograph shows bone condensation at the anterior proximal coated area. Figure lc - The components were very difficult to remove and had extensive adherent bone. Figure ld - Histology confirmed bone ingrowth.

Table I. Details of six patients who had revision of uncemented femoral prostheses for thigh pain

\begin{tabular}{|c|c|c|c|c|c|c|c|c|c|}
\hline \multirow[b]{2}{*}{ Case } & \multirow[b]{2}{*}{$\begin{array}{l}\text { Age } \\
\text { (yr) }\end{array}$} & \multirow[b]{2}{*}{ Sex } & \multirow[b]{2}{*}{$\begin{array}{l}\text { Original } \\
\text { diagnosis }\end{array}$} & \multirow[b]{2}{*}{ Implant } & \multirow[b]{2}{*}{$\begin{array}{l}\text { Time (mth) } \\
\text { implanted }\end{array}$} & \multicolumn{4}{|l|}{ Revision } \\
\hline & & & & & & $\begin{array}{l}\text { Ingrowth } \\
\text { (per cent) }\end{array}$ & Complication & $\begin{array}{l}\text { Follow-up } \\
\text { (mth) }\end{array}$ & Pain \\
\hline 1 & 61 & $\mathbf{F}$ & Fracture & $\mathbf{P C A} \mathbf{A}^{*}$ & 49 & 10 & None & 25 & Slight \\
\hline 2 & 73 & $\mathbf{F}$ & Fracture & AML bipolart & 61 & 8 & Shaft fracture & 29 & $\begin{array}{l}\text { Mild to } \\
\text { moderate }\end{array}$ \\
\hline 3 & 65 & $\mathbf{F}$ & Osteoarthritis & HGP & 14 & 50 & None & 60 & Mild \\
\hline 4 & 57 & $\mathbf{F}$ & Fracture & HGP bipolar $\ddagger$ & 6 & 22 & None & 31 & Slight \\
\hline 5 & 37 & $\mathbf{M}$ & $\begin{array}{l}\text { Slipped femoral } \\
\text { epiphysis: } 2^{\circ} \\
\text { osteoarthritis }\end{array}$ & HGP & 35 & 39 & None & 31 & Mild \\
\hline 6 & 53 & $\mathbf{M}$ & Osteoarthritis & HGP & 35 & 41 & $\begin{array}{l}\text { Calcar fracture } \\
\text { Femoral nerve palsy }\end{array}$ & 50 & Moderate \\
\hline
\end{tabular}

"porous-coated anatomic; Howmedica, Rutherford, New Jersey

tanatomic medullary locking; DePuy, Warsaw, Indiana

$\ddagger$ Harris-Galante prosthesis; Zimmer, Warsaw, Indiana 
some endosteal bone formation at the tip of the implant (Figs 1a,b). Repeated aspiration showed no sign of infection and an arthrogram was normal.

At surgery both components were well fixed and the femoral component was removed with great difficulty using thin osteotomes and a high-speed drill. The stem showed considerable adherent bone (Fig. 1c) and histology confirmed extensive bone ingrowth (Fig. 1d). A cemented stem was implanted. The postoperative course was uncomplicated and at two years the patient had occasional slight pain and used a cane only for long walks.

\section{DISCUSSION}

Pain and limping may be found in up to $40 \%$ of patients after uncemented arthroplasty, an incidence of residual symptoms much higher than in cemented arthroplasties (Haddad et al 1987; Callaghan et al 1988; Campbell et al 1992). Thigh pain is the most common complaint, with groin pain in a very small percentage (Hedley et al 1987; Haddad et al 1990). The pain seems to be related to the uncemented femoral stem rather than to the acetabular component, since hybrid total replacements have been reported not to have a propensity for thigh pain (Maloney and Harris 1990).

It has been assumed that a large amount of bone ingrowth would lead to clinical success. Engh et al (1987) reported that stabilisation by bone ingrowth gave better clinical results but the same group has also showed that $10 \%$ to $15 \%$ of their patients had significant symptoms in spite of the radiographic appearance of adequate ingrowth (Engh et al 1990). Our patients had stable, boneingrown prostheses but significant symptoms in the absence of infection. An inflammatory response to uncemented porous-coated implants has been reported in a small percentage of cases by Cook et al (1991), but none of our specimens showed inflammatory cells on histology.

All but one of the components in our series were porous-coated in only the proximal, metaphyseal portion of the implant. The remainder of the stems had a smooth or matt finish, and relative motion or abnormal stress transfer in the non-porous distal segment could have been a factor in producing persistent thigh pain. One of the stems, however, was coated in all but the distal $20 \%$ (Fig. 2), and the clinical history in this case was no different from the other five.

The cause of the thigh pain is not clear. After revision to a cemented stem all patients were improved but continued to have some symptoms (Table I). This can probably be attributed to the extensive revision procedure, since the removal of a well-fixed stem is an involved and sometimes destructive procedure. Two of the six patients had significant iatrogenic fractures at revision and these were the ones who had more than mild residual pain.
It has been suggested that pain from uncemented components may arise from their relative stiffness compared with bone, leading to non-physiological stress transfer (Skinner 1991). Symptoms have been reported to occur more often in uncemented femoral stems in which the ratio of flexural rigidity of implant to bone was higher (Skinner and Curlin 1990). Other important factors may be patient weight, stem size, geometry and stiffness (Skinner and Curlin 1990). In our series, two of the patients had cobalt-chrome implants (cases 1 and 2) while the other four had titanium stems which are about half as stiff.

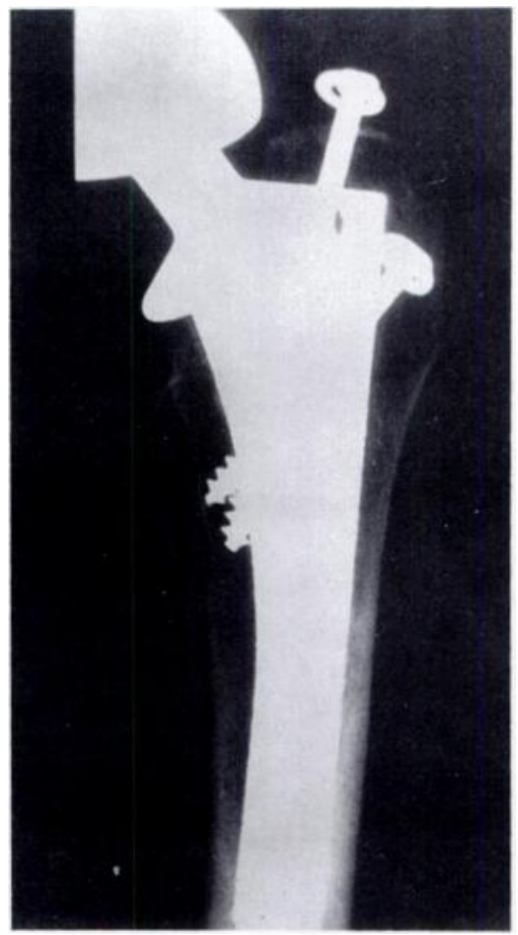

Fig. 2

Radiograph of a patient who had persistent pain and limping five years after the insertion of an uncemented AML prosthesis. There is a good fit and the radiographic appearance of bone ingrowth was confirmed histologically.

Our cases show that implant stability and good bone ingrowth do not guarantee the clinical success of an uncemented porous-coated femoral stem.

This study was supported by the William H. Harris Foundation, Boston. One or more of the authors have received or will receive benefits for personal or professional use from a commercial party related directly or indirectly to the subject of this article. In addition benefits have also been or will be directed to a research fund, foundation, educational institution, or other non-profit institution with which one or more of the authors is associated.

\section{REFERENCES}

Callaghan JJ, Dysart SH, Savory CG. The uncemented porous-coated anatomic total hip prosthesis: two-year results of a prospective consecutive series. J Bone Joint Surg [Am] 1988; 70-A:337-46. 
Campbell ACL, Rorabeck CH, Bourne RB, Chess D, Nott L. Thigh pain after cementless hip arthroplasty: annoyance or ill omen. $J$ Bone Joint Surg [ Br] 1992; 74-B :63-6.

Cook SD, Barrack RL, Thomas KA, Haddad RJ Jr. Quantitative analysis of tissue growth into human porous total hip components. $J$ Arthroplasty 1988; 3:249-62.

Cook SD, McCluskey LC, Martin PC, Haddad RJ Jr. Inflammatory response in retrieved noncemented porous-coated implants. Clin Orihop 1991 ; $264: 209-22$.

Engh CA, Bobyn JD, Glassman AH. Porous-coated hip replacement: the factors governing bone ingrowth, stress shielding, and clinical results. J Bone Joint Surg [ Br] 1987; 69-B:45-55.

Engh CA, Massin P, Suthers KE. Roentgenographic assessment of the biologic fixation of porous-surfaced femoral components. Clin Orthop 1990; 257:107-28.

Haddad RJ Jr, Cook SD, Thomas KA. Biological fixation of porouscoated implants: current concepts review. J Bone Joint Surg [ Am] $1987 ; 69-A: 1459-66$
Haddad RJ Jr, Skalley TC, Cook SD, et al. Clinical and roentgenographic evaluation of noncemented porous-coated anatomic medullary locking (AML) and porous-coated anatomic (PCA) total hip arthroplasties. Clin Orthop 1990; 258:176-82.

Hedley AK, Gruen TA, Borden LS, et al. Two-year follow-up of the PCA noncemented total hip replacement. Hip 1987; 225-50.

Jasty $M$, Bragdon $C R$, Schutzer $S$, et al. Bone ingrowth into porous coated canine total hip replacements: quantification by backscattered scanning electron microscopy and image analysis. Scanning Microsc 1989; 3:1051-7.

Maloney WJ, Harris WH. Comparison of a hybrid with an uncemented total hip replacement: a retrospective matched-pair study. J Bone Joint Surg [Am] 1990; 72-A :1349-52.

Skinner HB. Isoelasticity and total hip arthroplasty. Orthopedics 1991; 14:323-8.

Skinner HB, Curlin FJ. Decreased pain with lower flexural rigidity of uncemented femoral prostheses. Orthopedics 1990;13: 1223-8 